\title{
Rastreamento de fontes da contaminação microbiológica do leite cru durante a ordenha em propriedades leiteiras do Agreste Pernambucano
}

\section{Tracking sources of microbiologic contamination of raw milk during milking process in dairy farms from Agreste of Pernambuco}

\author{
Livia Cavaletti Corrêa da Silva ${ }^{1}$; Vanerli Beloti2 ${ }^{2}$; Ronaldo Tamanini ${ }^{1}$; \\ Loredana d'Ovidio ${ }^{3}$; Marcos Rodrigues de Mattos ${ }^{1}$; \\ Ana Maria Camelo Travassos de Arruda ${ }^{4}$ Edleide Maria Freitas Pires ${ }^{5}$
}

\begin{abstract}
Resumo
Os procedimentos empregados na ordenha são determinantes para a obtenção de leite de boa qualidade microbiológica. O estudo dos grupos de microrganismos contaminantes permite identificar sua origem, o que possibilita a adoção de medidas de controle de forma a atender os padrões estabelecidos pela legislação. O objetivo deste trabalho foi determinar os principais pontos de contaminação microbiológica do leite durante a ordenha. Para isso foram enumerados microrganismos aeróbios mesófilos (AM), psicrotróficos (PS), Estafilococos coagulase positiva (ECP), coliformes totais (CT) e Escherichia coli (EC) em diferentes pontos da ordenha em seis propriedades leiteiras e em um resfriador comunitário no Agreste Pernambucano, entre agosto e setembro de 2005. Constatou-se baixa qualidade microbiológica do leite indicada pelas altas contagens dos grupos de microrganismos pesquisados. As contagens médias de microrganismos nas amostras de leite nas propriedades leiteiras foram 8,3 $\times 10^{6}(\mathrm{AM}), 2,6 \times 10^{7}$ (PS), 1,3 x $10^{4}(\mathrm{ECP}), 2,5 \times 10^{5}(\mathrm{CT})$ e $3,7 \times 10^{3}$ (EC). No leite coletado no resfriador comunitário as contagens foram $6,1 \times 10^{7}(\mathrm{AM}), 3,4 \times 10^{7}$ (PS), 6,5 × $10^{4}$ (ECP), > $1,5 \times 10^{4}$ (CT) e 2,0 x $10^{3}$ (EC). Os pontos de maior contaminação identificados foram água residual do latão, fundo do latão, resfriador, tetos, três primeiros jatos de leite, teteiras, balde e mãos do ordenhador, sendo a principal causa da contaminação do leite o emprego inadequado ou a ausência de boas práticas de higiene na ordenha.

Palavras-chave: Qualidade, microrganismos indicadores, higiene de ordenha
\end{abstract}

\begin{abstract}
The procedures employed in milking process are determinant for obtaining milk with good microbiological quality. The study of contaminant microorganisms permits the identification of its source, what allows the adoption of control measures that will conform to the standards established by legislation. The aim of this work was to determine main points of milk microbiological contamination during milking process. For that mesophilic aerobes (MA), psychrotrophics (PS), coagulase positive Staphylococci (CPE), total coliforms (TC) and Escherichia coli (EC) were quantified in different steps of milking in six dairy farms and one communitarian bulk tank on Agreste region of Pernambuco,
\end{abstract}

\footnotetext{
1 Programa de Pós-Graduação em Ciência Animal, DMVP, CCA, Universidade Estadual de Londrina, UEL, Londrina-PR. Laboratório de Inspeção de Produtos de Origem Animal. E-mail: lipoa.uel@gmail.com

2 Docente do DMVP, CCA, UEL, Londrina-PR. E-mail: neli@sercomtel.com.br

3 Docente da Universidade Federal do Paraná, UFPR. E-mail loryovidio@ufpr.br

4 Responsável pelo Laboratório de Análises de Alimentos e Água, Garanhuns-PE. E-mail: lamensf@bol.com.br

5 Docente da Universidade Federal de Pernambuco, UFPE. E-mail: efpi@uol.com.br

Autor para correspondência
} 
between august and september of 2005. Poor microbiological milk quality was indicated by the high counts of the groups of microorganisms studied. The average counts of microorganisms in milk samples from the dairy farms were $8,3 \times 10^{6}(\mathrm{MA}), 2,6 \times 10^{7}(\mathrm{PS}), 1,3 \times 10^{4}(\mathrm{CPE}), 2,5 \times 10^{5}$ (TC) and 3,7 $\times 10^{3}$ (EC). In the milk collected from the communitarian bulk tank counts were $6,1 \times 10^{7}(\mathrm{MA}), 3,4 \times 10^{7}$ (PS), 6,5 x 10 $(\mathrm{CPE}),>1,5 \times 10^{4}(\mathrm{TC})$ and 2,0 $010^{3}$ (EC).Most contaminated points found were residual water of cans, the bottom of cans, bulk tank, teats, first three jets of milk, teatcups, bucket and milker's hands, and the main cause of milk contamination is improper employ or the absence of good hygiene practices during milking process.

Key words: Quality, indicator microorganisms, milking hygiene

\section{Introdução}

Pernambuco é o 9o estado brasileiro em produção leiteira e o 2o maior na região Nordeste. Em 2007, apresentou uma produção de 662 milhões de litros de leite. A atividade leiteira está concentrada principalmente na região Agreste, que representa $74,8 \%$ da produção do Estado (EMBRAPA, 2007; IBGE, 2007; TCE/PE, 2003). O Programa Leite de Pernambuco instituído em dezembro de 2000, parceria entre o Governo do Estado e o Governo Federal, descreveu em seu primeiro relatório problemas na qualidade do leite adquirido para distribuição em escolas e creches (TCE/PE, 2003).

A qualidade do leite cru no Brasil é considerada, em geral, insatisfatória associada às altas contagens de microrganismos aeróbios mesófilos, coliformes e psicrotróficos (MARTINS et al., 2008; PINTO; MARTINS; VANETTI, 2006; NERO et al., 2005; BUENO et al., 2004; SANTANA; BELOTI; BARROS, 2001). Os procedimentos empregados na ordenha determinam a qualidade microbiológica do leite, cada etapa nesse processo pode ser responsável pela inclusão de milhões de microrganismos no leite na ausência de boas práticas de higiene (SANTANA; BELOTI; BARROS, 2001). O estudo dos grupos de microrganismos presentes permite determinar a origem da contaminação.

O grupo dos microrganismos aeróbios mesófilos inclui a maioria das bactérias acidificantes do leite e os patógenos (FRANCO; LANDGRAF, 2008). A Instrução Normativa 51 (IN 51) estabelece, além de outras medidas, o resfriamento do leite após a ordenha (BRASIL, 2002). Essa prática reduz significativamente a multiplicação dos aeróbios mesófilos, porém, favorece a multiplicação da microbiota psicrotrófica (SANTANA; BELOTI; BARROS, 2001).

Apesar dos microrganismos psicrotróficos serem facilmente inativados pela pasteurização, suas enzimas proteolíticas e lipolíticas são termoresistentes e podem ser a causa de alterações no leite e derivados após o tratamento térmico (HAYES; BOOR, 2001; BRAMLEY; McKINNON, 1990).

O Staphylococcus aureus é o agente causador de mastite de maior ocorrência mundial (FAGUNDES; OLIVEIRA, 2004), consequentemente, é também um dos patógenos mais isolados do leite cru (SANTANAetal., 2006) eenvolvido emintoxicações de origem alimentar (WONG; BERGDOLL, 2002).

Enquanto os coliformes totais indicam contaminação proveniente do ambiente, a presença de Escherichia coli indica contaminação de origem fecal e presença de enteropatógenos (FRANCO; LANDGRAF, 2008).

Determinar a intensidade da contaminação desses microrganismos em cada ponto da ordenha permite determinar os principais pontos e a origem da contaminação, ou seja, ambiental, de origem fecal, por manipulação inadequada ou oriunda do animal e, qual o efeito das temperaturas de refrigeração na sua multiplicação. Isso possibilitará a adoção de medidas de controle que melhorem a qualidade microbiológica do leite, adequando-o aos padrões estabelecidos pela IN 51. 
Assim, este trabalho teve como objetivo municípios de São Bento do Una, Bom Conselho determinar os principais pontos de contaminação durante a ordenha, em propriedades leiteiras do agreste pernambucano.

\section{Material e Métodos}

No período de 24 de agosto a 29 de setembro de 2005, foram selecionadas seis propriedades nos

e Águas Belas, de forma que estas representassem as características de manejo, as instalações e a forma de produção da região. Foi avaliado ainda, um resfriador comunitário em Bom Conselho. As características das propriedades e práticas de ordenha encontram-se no Quadro 1.

Quadro 1. Características das propriedades leiteiras dos 3 municípios do Agreste Pernambucano no período de agosto e setembro de 2005.

\begin{tabular}{|c|c|c|c|c|c|c|}
\hline \multirow{2}{*}{$\begin{array}{c}\text { Município } \\
\text { Características/ Propriedade }\end{array}$} & \multicolumn{2}{|c|}{ São Bento do Uma } & \multicolumn{2}{|c|}{ Bom Conselho } & \multicolumn{2}{|c|}{ Águas Belas } \\
\hline & 1 & 2 & 3 & 4 & 5 & 6 \\
\hline No de Animais em lactação & 60 & 70 & 30 & 9 & 9 & 15 \\
\hline $\mathrm{N}^{\circ}$ de ordenhas diárias & 2 & 2 & 2 & 2 & 2 & 2 \\
\hline Produção média diária & $850 \mathrm{~L}$ & $800 \mathrm{~L}$ & $400 \mathrm{~L}$ & $27 \mathrm{~L}$ & $70 \mathrm{~L}$ & $100 \mathrm{~L}$ \\
\hline Tipo de ordenha & Mecânica & Manual & Manual & Manual & Manual & Manual \\
\hline Presença de bezerro & Sim & $\operatorname{Sim}$ & Sim & Sim & Sim & Sim \\
\hline Lavagem dos tetos & Não & Não & Não & Não & Não & Não \\
\hline Prática de pré-dipping & $\operatorname{Sim}^{1}$ & Não & Não & Não & Não & Não \\
\hline Prática de pós-dipping & $\operatorname{Sim}^{1}$ & Não & Não & Não & Não & Não \\
\hline Despreza os 31 os jatos & Sim & Não & Não & Não & Não & Não \\
\hline Realiza CMT & Não & Não & Não & Não & Não & Não \\
\hline Piso impermeável na ordenha & Sim & Não & Sim & Não & Não & Não \\
\hline Lavagem das mãos & Não & Não & Não & Não & Não & Não \\
\hline Fonte de água & Lagoa & Açude & Encanada & Mina & Rio & Açude \\
\hline Tratamento da água & Cloro & Não & Não & Não & Não & Não \\
\hline Resfria o leite & Não & Não & Não & Não & $\mathrm{Sim}^{2}$ & $\mathrm{Sim}^{2}$ \\
\hline Recolhimento do leite & Diário & Diário & Diário & Diário & Diário & Diário \\
\hline
\end{tabular}

1 Solução iodada (pré-dipping somente nos animais sem bezerro ao pé).

2 Resfriador comunitário.

Em cada propriedade os pontos foram escolhidos de acordo com o sistema de ordenha e práticas de higiene empregadas. Foram coletadas amostras do leite (três primeiros jatos e leite de conjunto), da água (na fonte e nos pontos de utilização), dos utensílios de ordenha (baldes e latões), dos equipamentos (teteiras e tanque de expansão), da água residual dos equipamentos e utensílios, das mãos do ordenhador e dos tetos.

Nos tetos e teteiras utilizou-se uma área de $3 \mathrm{~cm}^{2}$ de amostragem (SANTANA; BELOTI; BARROS,
2001). Nos latões e baldes a área amostrada foi de $100 \mathrm{~cm}^{2}$ e no resfriador, $500 \mathrm{~cm}^{2}$ (fundo e lateral). Foi feito swab das mãos do ordenhador. As áreas amostradas foram delimitadas utilizando-se moldes flexíveis de polietileno esterilizados produzidos pelo LIPOA (Laboratório de Inspeção de Produtos de Origem Animal - UEL).

Foram utilizados Quick swabs da 3M (St. Paul, MN, EUA), com caldo Letheen como meio de transporte, que neutraliza a ação de resíduos de sanificantes. Para coleta das amostras de leite e água 
foram utilizadas bags esterilizadas ( $\mathrm{Nasco}^{\circledR}$, EUA). As amostras foram mantidas sob temperatura de refrigeração e encaminhadas ao Laboratório de Analises de Alimentos e Água (LAMEN) em Garanhuns para realização das análises. No total foram coletadas 115 amostras.

Para pesquisa dos microrganismos indicadores, procedeu-se a diluição decimal seriada da amostra em solução salina esterilizada $0,85 \%$. As diluições selecionadas para cada microrganismo foram semeadas em placas Petrifilm ${ }^{\mathrm{TM}} \mathrm{AC}$ (para aeróbios mesófilos), STX (para Estafilococos coagulase positiva) e EC (para coliformes totais e E. coli), conforme recomendações do fabricante.

Para a contagem de psicrotróficos foi utilizado o método de semeadura em superfície, em duplicata, em ágar padrão para contagem (PCA) e incubados a $7^{\circ} \mathrm{C}$ por 10 dias (AMERICAN PUBLIC HEALTH ASSOCIATION, 2001).

Para verificar se houve aquecimento prévio do leite nas propriedades, foi realizada a prova da peroxidase de acordo com Brasil (2003).

\section{Resultados e Discussão}

As amostras de leite foram classificadas como de qualidade microbiológica ruim (Tabela 1) em função das altas contagens microbianas. Oito $(72,73 \%)$ das onze amostras de leite apresentaram contagens de aeróbios mesófilos acima de $10^{6} \mathrm{UFC/}$ $\mathrm{mL}$, imediatamente após a ordenha, sendo a média de $8,3 \times 10^{6} \mathrm{UFC} / \mathrm{mL}$.

As amostras de leite coletadas do resfriador comunitário, no início da refrigeração, apresentaram contagens de aeróbios mesófilos médias de 6,1 x $10^{7} \mathrm{UFC} / \mathrm{mL}$ e de psicrotróficos de $3,4 \times 10^{7} \mathrm{UFC} /$ $\mathrm{mL}$. Após 24 horas de refrigeração foi observado um aumento nas contagens para 4,5 x $10^{10} \mathrm{UFC} /$ $\mathrm{mL}$ e $7,3 \times 10^{8} \mathrm{UFC} / \mathrm{mL}$, respectivamente. A IN 51 determina a refrigeração do leite após a ordenha (BRASIL, 2002), no entanto, não estabelece padrões para contagem de psicrotróficos, indicador ideal para avaliação da qualidade microbiológica do leite refrigerado. A presença de peróxido de hidrogênio identificada em duas (18,2\%) amostras de leite significa que as contagens poderiam ser superiores às observadas.

Tabela 1. Contagens médias de microrganismos (UFC/mL) aeróbios mesófilos (AM), psicrotróficos (PS), coliformes totais (CT), Escherichia coli (EC), e Estafilococos coagulase positiva (ECP) de amostras de leite coletadas em seis propriedades leiteiras e um resfriador comunitário do Agreste Pernambucano, entre agosto e setembro de 2005.

\begin{tabular}{ccccccc}
\hline Ponto & AM & PS & CT & EC & ECP & $\mathbf{n}^{*}$ \\
\hline Leite de conjunto & $8,3 \times 10^{6}$ & $2,6 \times 10^{7}$ & $2,5 \times 10^{5}$ & $3,7 \times 10^{3}$ & $1,3 \times 10^{4}$ & 11 \\
Leite resfriador logo após a ordenha & $6,1 \times 10^{7}$ & $3,4 \times 10^{7}$ & $>1,5 \times 10^{4}$ & $2,0 \times 10^{3}$ & $6,5 \times 10^{4}$ & 1 \\
Leite resfriador após 24h refrigeração & $4,5 \times 10^{10}$ & $7,3 \times 10^{8}$ & $1,6 \times 10^{5}$ & $4,0 \times 10^{2}$ & $7,0 \times 10^{3}$ & 1 \\
\hline
\end{tabular}

* Número de amostras

As amostras de leite de conjunto foram coletadas das nas seis propriedades e em cinco latões recebidos no resfriador comunitário, em um total de 11 amostras.

Apenas duas das propriedades refrigeravam o leite em tanques comunitários. No Agreste Pernambucano $75,6 \%$ dos produtores não refrigeram o leite (MONTEIRO et al., 2007). A utilização de tanques comunitários, alternativa para pequenos produtores, pode acumular falhas individuais, o que prejudica a qualidade do leite refrigerado (BUENO et al., 2004). Ainda, a entrada constante de leite em temperatura ambiente no tanque, constatada neste estudo leva a redução da eficiência da refrigeração. Observou-se o aumento nas contagens de todos os grupos de microrganismos em 24 horas (Tabela 1) exceto $E$. coli e Estafilococos coagulase positiva.

O alto grau de contaminação do leite por 
microrganismos psicrotróficos implica em prejuízos econômicos e tecnológicos para a indústria. A proteólise causada por enzimas de bactérias psicrotróficas são associadas a problemas como gelificação do leite UHT e aumento da taxa de sedimentação (TOPÇU; NUMANOGLU; SALDAMLI, 2006), redução do rendimento da produção de queijos de até 20\% (SOUSA et al., 2007) com comprometimento da qualidade, redução da vida de prateleira e consequentes prejuízos financeiros para a indústria.

A maior parte das amostras de leite das propriedades apresentou altas contagens de Estafilococos coagulase positiva, em média 1,3 x $10^{4} \mathrm{UFC} / \mathrm{mL}$ (Tabela 1). No leite do resfriador comunitário ocorreu uma redução no número de Estafilococos coagulase positiva após a refrigeração que pode ser associada à presença de microbiota competidora (WONG; BERGDOLL, 2002; MARTIN; MYERS, 1994;). A população estimada de Estafilococos para produzir quantidade significativa de toxina é de 10\%/mL (FORSYTHE; HAYES, 1998) e, nas condições estudadas essa contagem não foi atingida com 24 horas de refrigeração.

De acordo com a literatura, contagens acima de $100 \mathrm{UFC} / \mathrm{mL}$ de bactérias do grupo coliforme indicam falhas na higiene durante e entre as ordenhas (CHAMBERS, 2002). A contaminação média por coliformes totais foi de $2,5 \times 10^{5} \mathrm{UFC} /$ $\mathrm{mL}$. A redução nas contagens de $E$. coli após a refrigeração (Tabela 1) e de Estafilococos coagulase positiva, pode estar associada à competição com a microbiota e refrigeração (FORSYTHE, 2002).

Os tetos sujos apresentaram em média 1,1 $\mathrm{x}$ $10^{5} \mathrm{UFC} / \mathrm{cm}^{2}$ de aeróbios mesófilos (Tabela 2). Considerando que os tetos têm uma área total de aproximadamente $50,8 \mathrm{~cm}^{2}$ (SANTOS; FONSECA, 2007), a contaminação por teto foi de $5,6 \times 10^{5}$ UFC e por vaca $2,2 \times 10^{7}$ UFC. Santana; Beloti e
Barros (2001) demonstraram que a incorporação de microrganismos do teto ao leite durante a ordenha varia entre 86 a $96 \%$.

$\mathrm{Na}$ propriedade 6 a limpeza do teto (Tabela 2) após o bezerro mamar era realizada com uma solução preparada pelo ordenhador por diluição de $5 \mathrm{~mL}$ de iodo a $5 \%$ em 2 litros de água não tratada. Um mesmo pano embebido na solução era utilizado para todos os animais e não era higienizado após o procedimento. Em um dos animais essa prática levou a um aumento de mais de mil vezes da população de microrganismos aeróbios mesófilos nos tetos, de 2,2 x $10^{4} \mathrm{UFC} / \mathrm{cm}^{2}$ para $2,5 \times 10^{7} \mathrm{UFC} / \mathrm{cm}^{2}$.

Os três primeiros jatos de leite (Tabela 2) apresentaram altas contagens para todos os grupos microbianos, portanto é um ponto importante a ser considerado para o controle da contaminação do leite. Apenas uma propriedade eliminava os três primeiros jatos de leite, porém em todas as propriedades havia a presença de bezerros, que mamavam antes da ordenha e dessa forma os três primeiros jatos eram eliminados. Os três primeiros jatos, que correspondem entre aproximadamente 100 e $150 \mathrm{~mL}$ de leite, contribuem para uma contaminação média adicional de 5,6 x $10^{4}$ UFC de aeróbios mesófilos por $\mathrm{mL}$ de leite, ou seja, pelo menos 5,6 x $10^{6}$ UFC por quarto e $2,2 \times 10^{7}$ UFC por animal que será somado integralmente à contaminação final do leite.

A presença de bezerros na ordenha, embora indesejável, foi observada em todas as propriedades. As contagens de microrganismos aeróbios mesófilos nos tetos após o bezerro mamar demonstraram um pequeno aumento no grau de contaminação, que pode ser reduzido por meio do pré-dipping (BRITO; BRITO; VERNEQUE, 2000). O bezerro foi útil em situações de ordenha nos piquetes, observadas nesse estudo, onde não há instalações adequadas e água, auxiliando na eliminação dos primeiros jatos e na remoção do excesso de matéria orgânica dos tetos, que prejudicaria a ação do cloro no pré-dipping. 
Tabela 2. Contagens médias de microrganismos $\left(\mathrm{UFC} / \mathrm{mL}\right.$ ou $\left.\mathrm{UFC} / \mathrm{cm}^{2}\right)$ aeróbios mesófilos (AM), psicrotróficos (PS), coliformes totais (CT), Escherichia coli (EC) e Estafilococos coagulase positiva (ECP) obtidas de tetos, leite e mãos de ordenhadores em seis propriedades leiteiras do Agreste Pernambucano entre agosto e setembro de 2005.

\begin{tabular}{|c|c|c|c|c|c|c|}
\hline Ponto & $\mathbf{A M}$ & PS & CT & EC & ECP & $\mathrm{n}^{*}$ \\
\hline Teto sujo & $1,1 \times 10^{5}$ & $1,8 \times 10^{4}$ & $1,9 \times 10^{2}$ & $2,4 \times 10^{1}$ & $1,4 \times 10^{4}$ & 13 \\
\hline Teto após bezerro mamar & $1,6 \times 10^{5}$ & $1,4 \times 10^{5}$ & $1,1 \times 10^{3}$ & $8,4 \times 10^{2}$ & $1,4 \times 10^{4}$ & 9 \\
\hline Teto após limpeza com panoa & $1,4 \times 10^{7}$ & $6,8 \times 10^{5}$ & $2,6 \times 10^{4}$ & $2,5 \times 10^{4}$ & $1,3 \times 10^{3}$ & 2 \\
\hline Teto limpo pré-dipping ${ }^{b}$ & $1,4 \times 10^{3}$ & $5,0 \times 10^{1}$ & 3,0 & 3,0 & $2,7 \times 10^{2}$ & 2 \\
\hline Três primeiros jatos de leite & $5,6 \times 10^{4}$ & $7,2 \times 10^{4}$ & $3,1 \times 10^{3}$ & $1,1 \times 10^{1}$ & $1,2 \times 10^{3}$ & 12 \\
\hline Mão do ordenhador antes da ordenha ${ }^{c}$ & $2,4 \times 10^{5}$ & $2,4 \times 10^{5}$ & $9,5 \times 10^{3}$ & $7,3 \times 10^{1}$ & $8,7 \times 10^{2}$ & 2 \\
\hline Mão do ordenhador depois da ordenha ${ }^{\mathrm{c}}$ & $4,4 \times 10^{4}$ & $1,0 \times 10^{4}$ & $2,0 \times 10^{1}$ & $2,0 \times 10^{1}$ & $5,6 \times 10^{3}$ & 2 \\
\hline
\end{tabular}

* Número de amostras

a. água com solução iodada, o mesmo pano era utilizado para a secagem dos tetos de todos os animais.

b. solução iodada (pré-dipping somente realizado nos animais sem bezerro ao pé).

A mão do ordenhador também foi identificada como importante ponto de contaminação do leite. Após a ordenha houve redução nas contagens, (Tabela 2), parte dessa contaminação provavelmente foi incorporada aos tetos e ao leite durante a ordenha, uma vez que as mãos não eram lavadas durante a ordenha.

As teteiras (Quadro 1) eram higienizadas ao final de cada ordenha apenas com água. Apresentaram alto grau de contaminação antes da ordenha e, durante a ordenha (Tabela 3) e, possivelmente essa contaminação foi transferida ao leite, visto que houve redução de microrganismos em sua superfície entre o início e o final da ordenha.
Os equipamentos e principalmente utensílios de ordenha como baldes e latões apresentaram altas contagens microbianas exceto para Estafilococos coagulase positiva, o que indica a existência de falhas nos procedimentos de higienização. Segundo Bramley e McKinnon (1990), equipamentos e utensílios de ordenha mal higienizados são a principal fonte de microrganismos psicrotróficos. Neste trabalho, o fundo dos latões e dos resfriadores e a água residual dos latões foram também as principais fontes de microrganismos psicrotróficos e aeróbios mesófilos. A contaminação por coliformes totais e E. coli foram predominantes no fundo e na água residual dos latões.

Tabela 3. Contagens médias de microrganismos $\left(\mathrm{UFC} / \mathrm{mL}\right.$ ou $\left.\mathrm{UFC} / \mathrm{cm}^{2}\right)$ aeróbios mesófilos (AM), psicrotróficos (PS), coliformes totais (CT), Escherichia coli (EC) e Estafilococos coagulase positiva (ECP) obtidas de equipamentos e utensílios de ordenha em seis propriedades leiteiras e um resfriador comunitário no Agreste Pernambucano entre agosto e setembro de 2005 .

\begin{tabular}{lcccccc}
\hline \multicolumn{1}{c}{ Ponto } & AM & PS & CT & EC & ECP & $\mathbf{n}^{*}$ \\
Teteira antes da ordenha & $2,3 \times 10^{5}$ & $4,2 \times 10^{5}$ & $5,3 \times 10^{1}$ & 3,0 & $3,3 \times 10^{1}$ & 2 \\
Teteira meio da ordenha & $2,6 \times 10^{4}$ & $1,7 \times 10^{4}$ & $7,3 \times 10^{2}$ & $3,3 \times 10^{1}$ & $6,8 \times 10^{2}$ & 2 \\
Teteira após a ordenha & $2,7 \times 10^{4}$ & $1,3 \times 10^{3}$ & $1,2 \times 10^{2}$ & $3,3 \times 10^{1}$ & $4,4 \times 10^{3}$ & 2 \\
Lateral latão & $9,1 \times 10^{4}$ & $4,6 \times 10^{4}$ & $1,2 \times 10^{3}$ & $4,0 \times 10^{1}$ & 2,6 & 5 \\
Fundo latão & $5,1 \times 10^{7}$ & $1,3 \times 10^{6}$ & $4,8 \times 10^{4}$ & $3,0 \times 10^{4}$ & 2,2 & 5 \\
Água residual do latão & $6,2 \times 10^{7}$ & $3,2 \times 10^{6}$ & $7,0 \times 10^{5}$ & $3,1 \times 10^{4}$ & $7,7 \times 10^{1}$ & 4 \\
Balde & $1,2 \times 10^{4}$ & $1,2 \times 10^{4}$ & $1,7 \times 10^{2}$ & $4,0 \times 10^{1}$ & 0,2 & 5 \\
Água residual do balde & $6,7 \times 10^{7}$ & $9,5 \times 10^{5}$ & $1,5 \times 10^{5}$ & $1,5 \times 10^{5}$ & $2,3 \times 10^{2}$ & 1 \\
Fundo do resfriador & $6,8 \times 10^{4}$ & $1,2 \times 10^{6}$ & $>5,0 \times 10^{3}$ & $>5,0 \times 10^{3}$ & 0,03 & 1 \\
Lateral do resfriador & $1,2 \times 10^{6}$ & $1,6 \times 10^{7}$ & $>7,5 \times 10^{3}$ & $>7,5 \times 10^{3}$ & $<0,5$ & 1 \\
\hline
\end{tabular}

*Número de amostras 
A água residual (Tabela 3) foi o ponto de contaminação mais importante pela concentração de microrganismos encontrada e pelo fato dessa contaminação ser totalmente incorporada ao leite. Observou-se uma média de $96 \mathrm{~mL}$ de água residual em cada latão, a contagem média de microrganismos aeróbios mesófilos na água residual foi de $6,2 \mathrm{x}$ $10^{7} \mathrm{UFC} / \mathrm{mL}$, que contribuiria para o aumento da contagem para $6,0 \times 10^{9}$ UFC/latão. Além dos microrganismos aeróbios mesófilos, a água residual foi a principal fonte de microrganismos psicrotróficos, coliformes totais e E. coli, o que reforçou a importância da sua eliminação.

Nenhuma das amostras de água estava de acordo com os padrões microbiológicos da Portaria $n^{\circ}$ 518, de 25 de março de 2004 (BRASIL, 2004), que estabelece para a água de consumo humano a ausência de coliformes totais e de E. coli em $100 \mathrm{~mL}$ de água. As médias das contagens foram 2,3 x $10^{2}$ $\mathrm{UFC} / \mathrm{mL}$ para coliformes totais e 2,0 x $10^{2} \mathrm{UFC} / \mathrm{mL}$ para $E$. coli na água utilizada para higienização dos equipamentos e utensílios. No entanto, com exceção da propriedade 1, em nenhuma propriedade a água era tratada, sendo coletadas diretamente de açudes, cisternas e minas. A inexistência de tratamento de água pode contribuir para contaminação dos utensílios e equipamentos de ordenha higienizados com essa água e comprometer a qualidade do leite.

\section{Conclusões}

O leite cru da região Agreste de Pernambuco apresentou qualidade microbiológica ruim, verificada por meio das altas contagens dos microrganismos estudados. A principal causa das altas contagens nas propriedades estudadas foi $\mathrm{o}$ emprego inadequado ou a ausência de boas práticas de higiene na ordenha.

Os pontos de maior contaminação em ordem decrescente foram a água residual do latão, fundo do latão, resfriador, tetos, três primeiros jatos, teteiras, balde e mãos do ordenhador. Esses pontos diferem dos principais pontos de ocorrência de $S$. aureus, que foram os três primeiros jatos, tetos, leite da cisterna do úbere e mãos do ordenhador.

A água utilizada na ordenha se mostrou fora dos padrões recomendados, sendo também uma fonte de contaminação indireta do leite por meio da contaminação dos equipamentos e utensílios de ordenha.

As altas contagens de psicrotróficos indicaram que o resfriamento do leite, se implantado na ausência de práticas que reduzam esta contaminação, não terá o efeito esperado na melhoria da qualidade do leite.

\section{Agradecimentos}

A Financiadora de Estudos e Projetos (FINEP) e ao Ministério de Desenvolvimento Social e Reforma Agrária (MDS). Esta pesquisa faz parte do Projeto "Produção de leite com qualidade e segurança a partir da implantação de boas práticas na produção leiteira na região de Recife, Pernambuco", financiado por estes órgãos. Ao Laboratório de Experimentação e Análises de Alimentos (LEAAL) da Universidade Federal de Pernambuco (UFPE) e ao Laboratório de Análises de Alimentos e Água (LAMEN), pelo apoio laboratorial. À Cooperativa dos Produtores de Leite e Derivados de Pernambuco (COOPROL) e à Secretaria de Produção Rural e Reforma Agrária de Pernambuco (SPRRA) pelo fornecimento de informações e pelo auxílio na seleção das propriedades estudadas.

\section{Referências}

AMERICAN PUBLIC HEALTH ASSOCIATION APHA. Committee on microbiological methods for foods. Compendium of methods for the microbiological examination of foods. 4. ed. Washington: APHA, 2001.

BRAMLEY, A. J.; McKINNON, C. H. The microbiology of raw milk. In:_. Dairy microbiology. 2. ed. England: Elsevier Science, 1990. v. 1, p. 163-208.

BRASIL. Ministério da Agricultura, Pecuária e Abastecimento. Instrução Normativa n.51 de 18 de setembro de 2002. Regulamento Técnico de Produção, 
Identidade e Qualidade de Leite Tipo A, Tipo B, Tipo C e Cru refrigerado. Diário Oficial [da] República Federativa do Brasil, Brasília, 29 set. 2002. Seção 1, p. 13.

Instrução Normativa n.22 de 14 de abril de 2003. Oficializa os Métodos Analíticos Oficiais FísicoQuímicos, para Controle de Leite e Produtos Lácteos. Diário Oficial [da] República Federativa do Brasil, Brasília, 2 maio 2003. Seção 1, p. 3.

Ministério da Saúde. Portaria n. 518 de 25 de março de 2004. Estabelece os procedimentos e responsabilidades relativos ao controle e vigilância da qualidade da água para consumo humano e seu padrão de potabilidade, e dá outras providências. Diário Oficial [da] República Federativa do Brasil, Brasília, 25 mar. 2004. n. 59, p. 266-270.

BRITO, J, R. F.; BRITO, M. A. V. P.; VERNEQUE, R. S. Contagem bacteriana da superfície de tetas de vacas submetidas a diferentes processos de higienização, incluindo a ordenha manual com participação do bezerro para estimular a descida do leite. Ciência Rural, Santa Maria, v. 30, n. 5, p. 847-850, 2000.

BUENO, V. F. F.; MESQUITA, A. J.; OLIVEIRA, J. P.; NICOLAU, E. S.; OLIVEIRA, A. N.; NEVES, R. B. S.; MANSUR, J. R. G. Influência da temperatura de armazenamento e o sistema de utilização de tanque de expansão sobre a qualidade microbiológica do leite cru. Revista Higiene Alimentar, São Paulo v. 18, n. 124, p. 62-67, set. 2004.

CHAMBERS, J. V. The microbiology of raw milk. In: ROBINSON, R. K. Dairy microbiology handbook: the microbiology of milk and milk products. 3. ed. New York: John Wiley and Sons, 2002. p. 39-90.

EMPRESA BRASILEIRA DE PESQUISA AGROPECUÁRIA - EMBRAPA. Ranking da produção anual leite por Estado no Brasil, 2007. Disponível em: <http://www.cnpgl.embrapa.br/nova/informacoes/ estatisticas/producao/tabela0240.php>. Acesso em: 26 nov. 2008 .

FAGUNDES, H.; OLIVEIRA, C. A. F. Infecções intramamárias causadas por Staphylococcus aureus e suas implicações em saúde pública. Ciência Rural, Santa Maria, v. 34, n. 4, p. 1315-1320, jul./ago. 2004.

FORSYTHE, S. J. Microbiologia da segurança alimentar. Porto Alegre: Artmed. 2002.

FORSYTHE, S. J.; HAYES, P. R. Food hygiene, microbiology and HACCP. In: Food poisoning and other food-borne hazards. $3^{\text {th }}$ ed. Maryland: Aspen, 1998. p. 36-39.
FRANCO, B. D. G. M.; LANDGRAF, M. microbiologia dos alimentos. 2. ed. São Paulo: Atheneu, 2008.

HAYES, M. C.; BOOR, K. Raw milk and fluid milk products. In:_. Applied dairy microbiology. $2^{\text {th }} \mathrm{ed}$.

New York: Marcel Dekker, 2001. p. 59-76.

INSTITUTO BRASILEIRO DE GEOGRAFIA E ESTATÍSTICA - IBGE. IBGE Estados, Pernambuco: pecuária 2007. Disponível em: <http://www.ibge.gov. $\mathrm{br} /$ estadosat/temas.php?sigla $=$ pe\&tema $=$ pecuaria2007 $>$. Acesso em: 26 nov. 2008.

MARTIN, S. E.; MYERS, E. R. Foodborne disease handbook: diseases caused by bacteria. New York: Marcel Dekker, 1994. v. 1, p. 345-394.

MARTINS, M. E. P.; NICOLAU, E. S.; MESQUITA, A. J.; NEVES, R. B. S.; ARRUDA, M. T. Qualidade de leite cru produzido e armazenado em tanques de expansão no estado de Goiás. Ciência Animal Brasileira, v. 9, n. 4, p. 1152-1158, out./dez. 2008.

MONTEIRO, A. A.; TAMANINI, R.; CAVALETTI, L. C. S.; MATTOS, M. R.; MAGNANI, D. F.; OVIDIO, L.; NERO, L. A.; BARROS, M. A. F.; PIRES, E. M. F.; PAQUEREAU, B. P. D.; BELOTI, V. Características da produção leiteira da região do Agreste do Estado de Pernambuco, Brasil. Semina: Ciências Agrárias, Londrina, v. 28, n. 4, out./dez. 2007.

NERO, L. A.; MATTOS, M. R.; BELOTI, V.; BARROS, M. A. F.; PINTO, J. P. A. N.; ANDRADE, N. J.; SILVA, W. P.; FRANCO, B. D. G. M. Leite cru de quatro regiões leiteiras brasileiras: perspectivas de atendimento dos requisitos microbiológicos estabelecidos pela Instrução Normativa 51. Ciência e Tecnologia de Alimentos, Campinas, v. 25, n. 1, p. 191-195, jan./mar. 2005.

PINTO, C. L. O.; MARTINS, M. L.; VANETTI, M. C. D. Qualidade microbiológica de leite cru refrigerado e isolamento de bactérias psicrotróficas proteolíticas. Ciência e Tecnologia de Alimentos, Campinas, v. 26, n. 3, p. 645-651, jul./set. 2006.

SANTANA, E. H. W.; BELOTI, V.; BARROS, M. A. F. Microrganismos psicrotróficos em leite. Revista Higiene Alimentar, São Paulo, v. 15, n. 88, p. 27-33, set. 2001.

SANTANA, E. H. W.; BELOTI, V.; OLIVEIRA, T. C. R. M.; MORAES, L. B.; TAMANINI, R.; SILVA, W. P. Estafilococos: morfologia das colônias, produção de coagulase e enterotoxina a, em amostras isoladas de leite cru refrigerado, Semina: Ciências Agrárias, Londrina. v. 27, n. 4, p. 639-646, out./dez. 2006.

SANTOS, M. V.; FONSECA, L. F. L. Estratégias para controle de mastite e melhoria da qualidade do leite. São Paulo: Manole, 2007. 
SOUSA, A. G.; NORONHA, J. F.; MOURA, C. J.; FIGUEIREDO, F. S.; CRUZ, A. F. Influência da qualidade do leite sobre os custos de uma indústria de laticínios em Goiás. In: CONGRESSO DA SOBER, 14., 2007, Londrina. Anais... Londrina: SOBER. 2007. Disponível em: <http://www.sober.org.br/palestra/6/192. pdf>. Acesso em: 03 fev. 2009.

TRIBUNAL DE CONTAS DO ESTADO DE PERNAMBUCO - TCE/PE. Secretaria de produção rural e reforma agrária. Programa leite de Pernambuco: relatório de auditoria de natureza operacional, 2003. 56 p. Disponível em: <http://www.tce.pe.gov.br/ANOP/ files_audi/progleite_anop.pdf $>$.Acesso em: 26 out. 2008.

TOPÇU, A.; NUMANOGLU, E.; SALDAMLI, I. Proteolysis and storage stability of UHT milk produced in Turkey. International Dairy Journal, Barking, England, v. 16, p. 633-638, 2006.

WONG, A. C. L.; BERGDOLL, M. Staphylococcal food poisoning. In: Foodborne diseases. 2. ed. Califórnia: Elsevier Science Publishers, 2002. p. 231248. 
